\title{
La Historia y su apreciación en sus fuentes inmediatas: el Saco de Roma en el carteggio de Francesco Guicciardini y los Diarii de Marino Sanudo
}

\author{
Appreciation of History in its Immediate \\ Sources: The Sack of Rome, the Carteggio \\ by Francesco Guicciardini \\ and the Diarii by Marino Sanudo
}

\section{Hélène Miesse}

Universidad de Lieja, Transitions

Unité de Recherches sur le Moyen Âge et la première Modernité 
El Saco de Roma cimbró la confianza de Occidente en la intangibilidad de los territorios vaticanos. En un ejercicio de comparación entre diversas fuentes -centrado en la visión de dos autores que contribuyeron a la escritura de la historia en el Renacimiento- este artículo desmonta el mecanismo por el cual ambos relatan para dar cuenta de las exacciones de las tropas imperiales, invasores indeseables de la península itálica. Con énfasis específico en la relación diacrónica entre el epistolario de Guicciardini, sus discursos apologéticos y la reflexión que subyació a la redacción de su Historia de Italia, se apuntala la visión de la lenta gestación de una escritura destinada a explicar razonadamente las decisiones tomadas para deslindar responsabilidades en los hechos narrados, y la importancia de las epístolas escritas al calor de los sucesos. Por otra parte, la profusión de fuentes y el rechazo explícito de una hermenéutica de las mismas, en el caso de los Diarios de Marino Sanudo, es leída como testimonio de la confusión vivida por la población italiana en los días posteriores, la imagen negativa de los soldados y su crueldad. Estas miradas cruzadas representan un ejercicio de cómo el análisis de las fuentes sincrónicas en su proceso de gestación permite arrojar nuevas luces e interpretaciones sobre la escritura de la Historia.

Palabras clave

Abstract
Francesco Guicciardini; carteggio; Marino Sanudo; Diarii; Saco de Roma, 1527.

The Sack of Rome shook the Western world's confidence in the intangibility of Vatican territories. In a comparison exercise several sources, focused on the points of view of two authors who contributed to the writing of history during the Renaissance, this paper disarms the mechanism through which both authors built their narrations, to account for the exactions of imperial troops, undesirable invaders of the Italian Peninsula. With specific emphasis in the diachronic relation between Guicciardini's epistolary, his apologetic speeches and the underlying considerations of the writing of his Historia de Italia, this article enhances the view of the slow development of a writing destined to reasonably explain the decisions taken to demarcate responsibilities for the facts narrated, and the importance of letters written in the heat of the moment. The abundance of sources and the patent rejection of its hermeneutic approach in the case of the Diarios, a work by Marino Sanudo, are read here as a testimony of the confusion experienced by the Italian population in the aftermath of the event, the negative image of the soldiers and their cruelty. These contested visions represent an example of how a synchronic sources analysis during their development process provides new light and interpretations on the writing of History. 
Escritores activos en la época de transición entre los siglos XV y XVII, Francesco Guicciardini y Marino Sanudo comparten la misma voluntad de plasmar sobre papel y diseccionar por medio de la escritura los conflictos que sacudieron la península itálica a partir de la llegada de las tropas de Carlos VIII durante la primavera de 1494. También comparten, además de la autoría de textos históricos, una importante producción a la que se puede tachar de "informal" - puesto que no responde ni a un cuidado específico de construcción de relato ni a imperativos estéticos-, material informativo que da acceso a la historia en pleno desarrollo durante uno de los periodos críticos del pasado europeo.

En el caso de Guicciardini se trata de su carteggio, la abundante correspondencia que redactó a lo largo de su carrera política; Marino Sanudo se refiere a sus Diarii, amplio conjunto documental que construyó esperando que le fuera encargada la redacción de la historia oficial de la república de Venecia. ${ }^{1}$

En este artículo ${ }^{2}$ me propongo cruzar la mirada de estos dos hombres coetáneos acerca de un acontecimiento preciso, particularmente doloroso, el Saco de Roma de 1527, el cual daría pie a una producción histórica y literaria muy abundante en los años subsecuentes, ${ }^{3}$ la cual analiza documentos de gran actualidad que reflejan la visión sin mediación de dos patricios de origen muy diverso que

\footnotetext{
${ }_{1}$ Puesto que ambos historiógrafos lograron construir corpus de millares de páginas cada uno, limité este estudio al periodo de intensa actividad que fue el mes de mayo de 1527, es decir, los días que precedieron y siguieron inmediatamente al Saco de Roma. Se podrá leer allí la angustia del desastre inminente y la descripción de las primeras semanas del pillaje. Se basa en el volumen 14 de la edición de Pier Giorgio Ricci de los carteggi de Guicciardini y el volumen 45 de la edición de Rinaldo Fulin, Federico Stefani, Niccolò Barozzi, Guglielmo Berchet y Marco Allegri de los Diarii de Marino Sanudo, citados en adelante con los títulos de carteggi y el número de página, y los Diarii con número de columna. Los fragmentos se citan en el idioma original en el texto y con mi traducción en nota al pie de página. [N. E.: la traducción francés-español de este artículo fue elaborada por la doctora Laurette Godinas]. 2 El punto de partida de este artículo fue una ponencia en el coloquio Encuentros/ Desencuentros. Italia y España en los siglos XV y XVI. Textos y contextos, el cual tuvo lugar en la Universidad Nacional Autónoma de México los días 26 y 27 de octubre de 2009.

${ }^{3}$ Es tal la producción crítica al respecto que sólo menciono unos estudios centrales y remito al lector a la bibliografía que en ellos se maneja. Véanse, entre otros estudios, el de Judith Hook, The Sack of Rome (Londres: MacMillan, 1972); Giovanna Solari, Il sacco di Roma (Milán: Mondadori, 1981); Andrea Frediani, II sacco di Roma (Florencia: Giunti, 1997); Kenneth Gouwens y Sheryl E. Reiss (eds.), The Pontificate of Clement VII. History, Politics,
} 
se vieron implicados de distintos modos en los asuntos de su tiempo. Esta confrontación nos permitirá, a la vez, medir el grado de conciencia de ambos frente a los acontecimientos que narran, y analizar el modo en el que dan cuenta -o no- de ellos en sus escritos inmediatos y/o posteriores, según el caso. La narración de las "extremas miserias y calamidades", 4 de la "ruina de Roma", 5 por retomar dos de las expresiones empleadas por nuestros autores en referencia a la situación romana, será, pues, el punto de partida para una reflexión sobre las modalidades del tratamiento de la información.

Culture (Aldershot: Ashgate, 2005). Acerca del impacto cultural del acontecimiento remito a André Chastel, Le sac de Rome, 1527. Du premier maniérisme à la contre-réforme (París: Gallimard NRF, 1984); Massimo Miglio, Vincenzo de Caprio, Daniel Arasse y Aberto Asor Rosa (eds.), Il Sacco di Roma del 1527 e l'immaginario collettivo (Roma: Istituto Nazionale di Studi Romani, 1986), así como el volumen compilado por Augustin Redondo, Les discours sur le sac de Rome de 1527, pouvoir et littérature (París: PSN, 1999). Por lo que respecta a los relatos de coetáneos, pueden consultarse los textos catalogados, publicados y/o analizados por Carlo Milanesi, Il sacco di Roma del MDXXVII. Narrazioni di contemporanei (Florencia: Barbèra, 1867); Emilio Calvi, Bibliografia di Roma nel Cinquecento (Roma: Loescher, 1910); Marco Bardini, Borbone occiso: studi sulla tradizione storiografica del sacco di Roma del 1527 (Pisa: Tip. Editrice Pisana, 1991); Kenneth Gouwens, Remembering the Renaissance: Humanist Narratives of the Sack of Rome (Leiden: Brill, 1998); Marina Marietti, "L'évocation du sac de Rome par le florentin Francesco Vettori", en Redondo, Les discours sur le sac de Rome... 69-81 y Antonio di Pierro, Il sacco di Roma: 6 maggio 1527 (Milán: Mondadori, 2003).

4 "Alle extreme miserie et calamità ci troviamo" (Diarii, 163).

5 "li quali affirmano pur la ruina di Roma" (Diarii, 181). En la obra de Guicciardini se leen las expresiones "rovinato el mondo" (carteggi, 23) y "in modo che questa via rovinerebbe un mondo ..." (carteggi, 4); "non cesserà di ruinare ogni cosa..." (carteggi, 10); "et andrà in ruina ogni cosa" (carteggi, 11); "Non si dimentichi per lo amore di Dio la persona di Sua Sanctità, perché da qcesto depende la salute o ruina del tutto" (carteggi, 37). Como lo subrayó oportunamente Giulia Ponsiglione en su libro La "Ruina" di Roma. Il Sacco del 1527 e la memoria letteraria (Roma: Carocci, 2010), la palabra "ruina" es característica de lo que ella llama "la retórica del Saco". Ha sido, por consiguiente, integrada en el título de estudios vinculados con este acontecimiento y su recepción en la diacronía, como el de Marina Marietti, "La 'ruine de l'Italie'. La fin tronquée des Istorie Fiorentine de Machiavel", en Danielle Boillet y Marie France Piéjus (eds.), Les guerres d'Italie (París: Presses Sorbonne Nouvelle, 2002, 337-351); la tesis de Samanta Quattrocchi, "'La ruina di questa desolatissima città': il sacco di Roma visto da Marin Sanudo" (Universidad de Padua, 2015), o el propio trabajo de Ponsiglione. 
Se io non volessi prima essere morto che vedere tanta crudeltà ${ }^{6}$

\section{Francesco Guicciardini y el carteggio}

Francesco Guicciardini (1483-1540), de origen florentino, antes de ejercer la pluma fue un actor político de primera importancia, primero al servicio de su ciudad -que lo nombró embajador en España-, luego fue gobernador de la Romaña (actual Emilia-Romaña) y, finalmente, ministro del papa Clemente VII, para quien fungió en primer lugar como consejero y posteriormente en calidad de lugarteniente general, un papel clave en el que brilló por su capacidad estratégica y autoridad. ${ }^{7}$ Guicciardini se convirtió así en uno de los principales artífices de la Liga de Cognac, cuyo destino se selló en dicha ciudad a principios de 1526 para resistir la influencia imperial en los asuntos de la península itálica. Esta misma alianza será puesta en entredicho por el Saco de Roma en 1527. ${ }^{8}$ La correspondencia fue para Guicciardini el modo de acción más importante: escribió para informar, recibir la aprobación de sus superiores acerca de las decisiones tomadas o por tomar, obtener fondos y refuerzos, desplazar a las tropas, etc. Aunque aún se espera su edición completa, las cartas de Guicciardini cubren el periodo de 1499 a 1540 y brindan a los lectores una ojeada a la historia de los poderosos tal y como se concibió desde las antesalas del poder, inaccesibles al común de los mortales. Resulta de gran interés ver cómo Guicciardini, quien más adelante en su Consolatoria, Accusatoria y Defensoria, ${ }^{9}$ así como en su monumental Historia de Italia, ${ }^{10}$ evocaría el Saco de Roma, acontecimiento de gran trascendencia tanto para Italia como para su carrera política; con una distancia crítica, a modo de un intelectual arrepentido,

\footnotetext{
${ }^{6}$ (Carteggi, 41): "Preferiría estar muerto antes que ver tanta crueldad".

7 Por lo que respecta a la trayectoria vital de Guicciardini, remito a la entrada homónima del Dizionario biografico degli Italiani y a la biografía de Roberto Ridolfi, Vita di Francesco

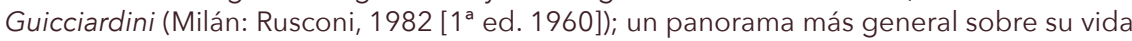
y obra, acompañado de una bibliografía crítica, podrá encontrarse en Emanuele CutinelliRèndina, Guicciardini (Roma: Salerno, 2009).

${ }^{8}$ Esta alianza, que unía al papado con las repúblicas de Florencia (gobernada por los Médici) y Venecia, el ducado de Milán, Francia e Inglaterra, no logró impedir que el ejército alemán y español de Carlos $V$ se dirigiera hacia Roma y llevara a cabo, durante los primeros días de mayo de 1527, lo que es recordado como el peor saqueo de la historia moderna.

${ }^{9}$ Guicciardini, Consolatoria, Accusatoria et Defensoria (París: Classiques Garnier, 2013).

${ }^{10}$ Guicciardini, Opere (Turín: UTET, 1970, vols. 2 y 3); para la traducción francesa, Histoire d'Italie, trad. Jean-Louis Fournel y Jean-Claude Zancarini (París: Robert Laffont, 1996), 2 vols. La falta de traducciones recientes al español de sus obras más relevantes es sintomática del relativo desinterés de la crítica hispánica hacia Guicciardini.
} 
de cierto modo, da en su correspondencia, aún parcialmente inédita, ${ }^{11}$ una imagen completamente distinta en sus escritos producidos al fragor de la acción.

Para el periodo seleccionado, el mes de mayo de 1527, sólo encontramos un número relativamente limitado de cartas, unas 30, cuando por lo general el lugarteniente de Clemente VII redactaba un promedio de 100 misivas al mes. ${ }^{12}$ Esta disminución en la producción epistolar se explica, entre otras razones, por los incesantes movimientos del ejército en campaña en el cual se encuentra Guicciardini, que le dejan poco tiempo para escribir, siempre "con las botas puestas"13 y en situación de total carencia de los medios adecuados; en efecto, Guicciardin acota en otra carta que escribiría diariamente si estuviera en sus manos hacerlo, pero no tiene a su disposición "ni correos, ni diligencia, ni orden"; ${ }^{14}$ Subraya, asimismo, lo complicados que son los intercambios epistolares cuando las carreteras están cerradas por todas partes, ${ }^{15}$ y los sobres son regularmente interceptados. Entre las cartas que subsistieron de dicha época encontramos cuatro que evocan de manera significativa la toma de la Ciudad Eterna por los enemigos de la Liga. ${ }^{16} \mathrm{La}$ primera tiene fecha del 8 de mayo de 1527, dos días después del inicio del pillaje, mientras que la última es del 16 de mayo, apenas una semana después. En las cartas que siguen, la preocupación principal será la manera de liberar al papa de su encarcelamiento en el Castillo Sant'Angelo. Esta relativa austeridad de la des-

${ }^{11}$ Guicciardini, Le lettere (Roma: Istituto Storico Italiano per I'Età Moderna e Contemporanea, 1986-2008), 10 vols. La publicación de las cartas es una empresa que continúa Paola Moreno, bajo la dirección de Pierre Jodogne. Después de un periodo de latencia debido a contratiempos de índole económica, que suele enfrentar este tipo de empresas editoriales, el volumen 11, en el cual se publican las cartas enviadas y recibidas por Guicciardini entre el 21 de junio y el 31 de julio de 1526, está por salir, y el volumen 12 se encuentra en preparación.

${ }^{12}$ El 27 de diciembre de 1526, por ejemplo, Guicciardini mandó 11 cartas en un solo día.

13 "El di sopra fu scripto questa mactina con gli stivali in piede per andare a San Casciano" (carteggi, 14); el subrayado es mío.

14 "Scriverrei ogni di, se havessi modo di mandarle, ma qua non sono poste né diligentia né ordine" (carteggi, 13).

15 "Le strade sono ropte per tucto o da' soldati o da' paesani, in modo che non mi meraviglio che le lectere vadino in sinixtro" (carteggi, 19); "Scriverrò ogni di, ma è difficillimo mandare le lectere, perché le strade da ogni banda sono ropte" (carteggi, 25).

${ }^{16}$ Se trata de las cartas del 8 y 13 de mayo de 1527 al cardenal Silvio Passerini, pp. 19-21 y 26-29; del 10 de mayo a Francesco Maria della Rovere, pp. 23-25 y del 16 de mayo a los Ocho de Práctica, pp. 32-36. Una quinta carta, dirigida el 29 de mayo a Uberto Gambara, nuncio papal en la corte de Enrique VIII, lleva a cabo un diagnóstico de la situación dramática post eventum y de las perspectivas futuras, que son igual de dramáticas sin la intervención del monarca inglés. Las cartas en las que se evoca el Saco de forma anecdótica y sin detalles son, en cambio, más numerosas. 
cripción, dada la importancia que revistió el evento para sus contemporáneos, contrasta con la prolijidad que le dedica Sanudo en sus Diarii. Sin embargo, resulta fácil comprender por qué Guicciardini no desea explayarse acerca de un desastre del que puede ser considerado parcialmente responsable, al menos por su falta de anticipación, y que aprovechó más bien sus escritos para influir en el desarrollo de los acontecimientos. El encargo principal del lugarteniente del ejército coalicionado es liberar el Sumo Pontífice, para lo cual no es necesario describir las atrocidades de las que él mismo ha sido víctima, y es muy probable que considerara que sus otros interlocutores podrían haber recibido noticias por canales alternativos. ${ }^{17}$ En fin, de su discurso se infiere rápidamente que pormenorizar las fechorías de los saqueadores no tendría más efecto que acrecentar el dolor, y que las palabras no bastan para describir la amplitud de los daños, como veremos más adelante. ${ }^{18}$

Si en su correspondencia Guicciardini no da rienda suelta a su opinión sobre la masacre, refleja, sin embargo, la capacidad de análisis del florentino in media res. En una carta del 24 de abril dirigida al datario papal Gian Matteo Giberti, Guicciardini da a conocer el carácter inminente de un desastre político y militar en Florencia, ciudad que desde Milán el ejército imperial aún podría convertir en blanco. En dicha carta observa que solamente el temor de un ataque sangriento impide al pueblo florentino, cansado de financiar las campañas militares, derribar el gobierno que sólo conserva la apariencia de una república. ${ }^{19}$ Para prevenir cualquier asalto Guicciardini vigila durante un tiempo los desplazamientos de las tropas enemigas. El 29 de abril, cuando los lansquenetes se aprestan a marchar sobre Roma, el lugarteniente sigue sin conocer sus designios y escri-

\footnotetext{
17 "Credo che delle cose di qua Vostra signoria Reverendissima habbia notitia per avisi di altri" (carteggi, 76).

18 "Non mi voglio extendere ne' particulari del modo come le cose siano state condocte et passate, perché non serve a altro effecto che a raddoppiarmi el dolore, et penso che Vostra Signoria per altre vie harà potuto havere informatione di tucto. Basta che el povero Nostro Signore si truova in Castello destituto da ogni speranza che al presente l'habbiamo a soccorrere, et rimesso alla venuta de' nuovi soccorsi..." (carteggi, 79-80). El dolor ya había sido evocado en la carta a Gambara del 29 de abril (carteggi, 69). Ponsiglione subraya en su libro la paradoja característica de las narraciones del Saco, que se puede observar ya en las primeras cartas surgidas al calor del evento, de la inefabilidad de lo ocurrido a pesar de la necesidad de traducir en palabras la tragedia, La "Ruina" di Roma..., 26.

19 "Uno freno solo tiene che in questa desperatione non si faccia novità: della paura che s'ha delli Spagnoli, et del saccho" (carteggi, 5). En los hechos, el poder está en manos del cardenal de Cortona, Silvio Passerini, y de los jóvenes Médici, Ippolito y Alessandro (Albertini 1995).
} 
be de nuevo al datario: "Per li avisi che s'hanno insino a hora non pare che li inimici siano per venire sì presto alla via di Roma, ma per travagliare le cose di Thoscana. Dove se forse trovassimo difficoltà, potrebbono voltarsi di costà" (carteggi, 12). ${ }^{20}$

Cada nuevo día da lugar a nuevas conjeturas basadas en parámetros muy diversos, tales como las condiciones climáticas, susceptibles de alentar los desplazamientos; la viabilidad de los caminos con la artillería, la consecución de los recursos financieros necesarios para la retribución o la sustitución de los soldados:

Le gente sue [del duca di Urbino] sono vicine a 3 migla a Firenze, e Svizeri et Franzesi tra el Borgo et Decomano; et havevano insino non hierlaltro a accostarsi a Firenze, con ordine di passare hieri tucti innanzi et unirsi; ma perché non ci era danari da pagare, e Svizeri non si vollono muovere né non hierlaltro né hieri; né sono certo se lo faranno hoggi (carteggi, 9). ${ }^{21}$

Nada parecía favorecer la empresa del florentino. A las limitaciones logísticas se suma la falta de informaciones recientes y confiables, la ambición de los capitanes con los que Guicciardini debía convivir -en particular Francesco Maria della Rovere, duque de Urbino, comandante de las tropas venecianas- y la incompetencia del cardenal Passerini, responsable de la contribución florentina a la Liga de Cognac, que "quiere estar en todo y no sabe hacer nada", ${ }^{22}$ sobre todo cuando de abrir la bolsa se trata; todo ello sin contar las negociaciones que habían empezado y culminado en Roma en marzo, para ser retomadas en Florencia en abril, y siempre sin impacto real en la resolución del conflicto. ${ }^{23} \mathrm{De}$

\footnotetext{
20 "Según la información de la que se dispone hasta hoy, no parece que los enemigos estén dispuestos a llegar pronto a Roma, sino más bien a poner el desorden en Toscana. De lo cual podrían desistir si se les opusiera resistencia".

21 "Su gente [es decir, del duque de Urbino] están a sólo 3 millas de Florencia, los suizos y los franceses entre el río Borgo y el Decomano [...], pero porque no había dinero para pagarles, los suizos no quisieron moverse ni ayer ni antes de ayer, y no estoy seguro de que lo hagan hoy".

22 "perché Cortona vuole fare ogni cosa et non sa fare nulla, si parla delle faccende quando Dio vuole et non si concludono, et concluse non si exequiscono, in modo che questa via rovinerebbe un mondo" (carteggi, 3-4), pero también "mercé di questo corpassone di Cortona, el quale vuole fare ogni cosa et non sa fare nulla" (carteggi, 11).

${ }^{23}$ Véase al respecto Marina Marietti, "L'évocation du sac de Rome par le florentin Francesco Vettori", en Redondo, Les discours sur le sac de Rome..., 75. Guicciardini igualmente menciona las interminables negociaciones, que nunca desembocan en acuerdos contundentes.
} 
este modo, conforme avanzan las cartas Guicciardini se muestra particularmente perspicaz al poner por delante los elementos que lo hacen dudar de una salida positiva del conflicto. En efecto, subraya la incapacidad de los soldados del ejército de la coalición -sin paga y exhaustos- para llevar a cabo una guerra de larga duración. En sus palabras: "Le cose sono reducte in luogo che non si può più sperare di accordo: o vincere o morire; bisogna non perdonare a niente et non tardare più, poi che el tardare ci ha condocti in luogo che né pace possiamo havere né sostenere la guerra senza l'aiuto o di Dio o del caso" (carteggi, 13). ${ }^{24}$

Del mismo modo, pone de manifiesto la grave escasez de dinero, mientras que se suceden las promesas de donaciones y los errores sucesivos del duque de Urbino, quien antepone sus intereses personales a los de los aliados cuando decide, al dirigirse hacia Módena, "abandonar la cabeza, lugar en situación de peligro tan evidente, para salvar el meñique de la mano, que aún no está padeciendo". ${ }^{25}$

Todo concurre, pues, hacia la ruina, el "gran desorden"26 que el lugarteniente teme y que, para él, tomará forma en una carta del 8 de mayo (aunque el 5 del mismo mes Gian Matteo Giberti ya haya dejado vislumbrar un desplazamiento de las tropas imperiales hacia Roma). Al recibir noticia del ataque Guicciardini ordena que Guido Rangoni, capitán del ejército francés de la Liga, conduzca sus tropas hacia la ciudad santa, y al mismo tiempo manda que los soldados fran-

24 "Las cosas llegan a tal extremo que no se puede esperar ningún acuerdo: o vencer, o morir; no hay que perdonar nada ni tardar mucho, porque los retrasos nos han llevado a un punto en el que no se puede tener paz ni librar la guerra sin la ayuda de Dios o del azar". Acerca del papel que atribuye Guicciardini al azar, la fortuna, el destino y la providencia en el episodio del Saco, véase el artículo de Jean-Claude Zancarini, "'Questa miseranda tragedia': Le sac de Rome, la providence, la politique", Cahiers d'Études Italiennes 19 (2014): 111-125, acceso el 4 de septiembre de 2017, http://cei.revues.org/2142, donde el autor, con quien hemos intercambiado opiniones antes de la publicación de este artículo, integra los resultados del análisis que aquí propongo.

25 "Ma io non potrei dire a Vostra Signoria quanto mi sia dispiaciuto el disegno suo di andarsene a Modona, et di abbandonare el capo, posto in sì manifesto periculo, per salvare uno piccolo dito della mano che ancora non patisce" (carteggi, 21). Acerca del profundo desacuerdo entre Guicciardini y Francesco Maria della Rovere, véase mi libro Un laboratorio di carte. Il linguaggio della politica nel 'carteggio' di Francesco Guicciardini (Estrasburgo: ELiPhi, 2017). Otro acercamiento a las relaciones entre Rovere y Guicciardini puede encontrarse en Marcello Simonetta, "La Storia d'Italia del pennaruolo. Accuse autobiografiche contro Guicciardini", en Stefano U. Baldassarri y Alessandro Polcri, Encyclopaedia mundi. Studi di letteratura italiana in onore di Giuseppe Mazzotta (Florencia: Le Lettere, 2013) 113-147.

26 "non mutando modi, come non muterà, sarà uno dì causa di qualche grande disordine..." (carteggi, 14). 
ceses y venecianos restantes se le unan a la mayor brevedad. El 7 de mayo, el historiógrafo florentino aún piensa que la dificultad inherente al asalto de Roma podría haber orillado al enemigo a voltear hacia Siena y la Toscana, ${ }^{27}$ donde todavía se encuentran las fuerzas aliadas, que no se deciden a abandonar del todo el área sin planear una eventual retirada hacia Florencia: como lo dice Guicciardini, "dejar la Toscana en un peligro tan evidente no está bien, y no brindar ayuda [al papa] con todas nuestras fuerzas está mal". ${ }^{28}$

Si bien Guicciardini no se detiene mucho en el tema, es posible reconstituir a partir de sus cartas una cronología precisa de los hechos que iniciaron con la entrada a Roma por el Borgo el lunes 6 de mayo, al alba. Después de dos horas de combate, el Borgo y el Palazzo cayeron en manos enemigas. El mismo día, los soldados españoles se apoderaron del Trastevere y entraron a su vez a la ciudad, a las 11 de la noche, pasando por el Puente Sixto. Si nos atenemos a las misivas de los días 10 y 13 de mayo, saquearon la ciudad con numerosos homicidios e infinitas impiedades, ${ }^{29}$ cometiendo muchas ejecuciones y echando mano de toda índole de crueldad y acciones sacrílegas. ${ }^{30} \mathrm{El}$ papa, al ver a las tropas de Carlos de Borbón acercarse peligrosamente, se marchó hacia el Castillo Sant'Angelo. Guicciardini desaprobó esta decisión, considerando que la tragedia podría haberse evitado si el pontífice hubiera recibido el consejo de un colaborador prudente. Se puede, por tanto, inferir que achaca la suerte de la ciudad a una falta de previsión por parte del papa y sus ministros. Escribe al respecto: "Nostro Signore la mactina medesima si era ritirato in Castello, et era stato in opinione di andarsene a Hostia; ma per havere inteso da uno prigione la morte di Borbone, et che non confidavano di piglare Roma, si era lasciato, el povero Signore, volgere da quelli che lo consiglorno che non partissi" (carteggi, 23). ${ }^{31}$

\footnotetext{
27 "se la venuta del conte Guido et fanti che si mandorono con lui sarà stato in tempo, harà assicurato Roma, et che li inimici, vedendo la impresa difficile, ritornerebbono con la medesima celerità verso Siena" (carteggi, 7).

28 "el lasciare la Thoscana in manifesto pericolo non è bene, et el non soccorrere voi con tucte le forze è male" (carteggi, 18).

29 "ma continuando la victoria presono el dì medesimo Trastevere, et la sera a hore 23 entrorono per Ponte Xisto in Roma, la quale mandavano a saccho; et, secondo si è inteso, con molti homicidii et crudeltà infinite" (carteggi, 23).

30 "la quale [Roma] hanno sacheggiata, factovi occisione assai, et usato ogni spetie di crudeltà et di sacrilegii" (carteggi, 27).

31 "Nuestra Señoría [es decir, el papa] se había retirado esa misma mañana al Castillo [Sant'Angelo] con la idea de irse hacia Ostia; pero después de escuchar de un prisionero la noticia de la muerte de Carlos de Borbón y que los enemigos no estaban seguros de tomar Roma, se había dejado, el pobre Señor, influenciar por aquellos que le aconsejaban no partir".
} 
En efecto, el condestable Carlos de Borbón, quien encabeza los ejércitos enemigos, muere de un arcabuzazo durante el primer asalto; numerosos soldados imperiales perecen, mientras que entre los aliados las pérdidas son limitadas. Según Guicciardini el pueblo romano, al que se le propuso huir, decide quedarse para proteger al papa, lo cual sin duda representa para él una luz de esperanza, de igual modo que las informaciones según las cuales aún se puede pensar en una victoria, dado que "li inimici per la grandeza della preda, alla quale sono tucti intenti, et per le lascivie (ché hanno a boctino tucte le donne di Roma) sono in grandissimo disordine et in roptura tra loro, et che ne sono morti in questi assalti circa a 1500 de' buoni" (carteggi, 27). ${ }^{32}$

Las cartas que cubren el resto del mes dan cuenta de las negociaciones llevadas a cabo por Clemente VII con el propósito de conseguir la liberación de la ciudad, para la cual las propuestas que le habían sido hechas ponían como condición un precio exorbitante y un exilio del pontífice a España con sus prelados. Guicciardini y Guido Rangoni intentan elaborar una estrategia para salvar al papa, al tiempo que le garantizan una retirada sin complicaciones. Sin embargo, los problemas endémicos de la Liga no han desaparecido y la lentitud del flujo de dinero -acentuados por el derrocamiento del gobierno florentino, que Guicciardini aprueba y de cuya defensa ha sido uno de los principales adalides- no facilita la empresa. Entonces escribe el lugarteniente muy contrariado: "Et nondimanco in tanta confidentia vegga Vostra Signoria Reverendissima quanto vilmente si è perduta in uno dì a bactagla di mano Roma, et rovinato el mondo" (carteggi, 23). ${ }^{33}$ Después afirma que desea llevar a cabo lo que emprendió liberando al papa -puesto que de éste depende la salvación o destrucción de todo- ${ }^{34}$ antes de poner fin a su misión. El asalto duraría ocho meses y el papa tardaría hasta junio de 1528 para volver a instalarse en el Vaticano.

\footnotetext{
32 "Los enemigos están en desbandada y desacuerdo por la grandeza del botín, hacia el cual todos se volcaron, y de las lascivias (porque tienen como presa a todas las mujeres de Roma), y aproximadamente 1500 buenos [soldados] han muerto en este asalto".

33 "Vea Su Señoría se perdió de manera vil, en un solo día en un combate cuerpo a cuerpo, a Roma y cómo se arruinó el mundo".

34 "Non si dimentichi per lo amore di Dio la persona di Sua Sanctità, perché da questo depende la salute o ruina del tutto" (carteggi, 37).
} 
Sarebbe impossibile non solo narrare ma quasi immaginarsi le calamità di quella città Los escritos post res perditas: Orationes e Historia de Italia

Me parece importante, sin embargo, para entender mejor al hombre cabal que es Francesco Guicciardini y la perspicacia que lo caracteriza al enlistar las causas del fracaso de la Liga de Cognac, poner su correspondencia en perspectiva con los otros escritos en los cuales el autor hace referencia al drama del que fue, muy a pesar suyo, una especie de guionista. Se trata, por una parte, de las orationes fictae y, por la otra, de la Historia de Italia.

Los tres textos, que redactará en el otoño de 1527, conforman -como bien lo mostró Fournel- "un análisis inmediato de la derrota" que es al mismo tiempo personal, puesto que Guicciardini se ve forzado a abandonar sus funciones públicas, y colectiva, en la medida en que el Saco significó para los estados italianos el fin de su autonomía. ${ }^{35} \mathrm{Al}$ asumir sucesivamente las posturas del amigo que consuela, del fiscal y de la defensa en un proceso ficticio donde él es el acusado y en el cual debe rendir cuentas ante el pueblo de Florencia de lo que ocurrió bajo su mandato como lugarteniente, Guicciardini sólo se refiere brevemente al Saco, al inicio de la Consolatoria y posteriormente en la Accusatoria:

La calamità, la ruina di tutto el mondo non nasce da altri che da te. Per te è sbandito da tutti el nome santo della pace, el mondo tutto è in guerra, in arme, in fuoco. Per te è stata data in preda agl'infideli I'Ungheria; per te è andata Roma a sacco con tanta crudeltà, con tanta ruina universale e particulare di tanti nostri cittadini; per te gli eretici dominano e' luoghi santi; per te hanno gittate a' cani le reliquie. ${ }^{36}$

Abundan en estos textos las imágenes de la ruina, también recurrente en las cartas, pero lo que importa para el autor en ellos no es tanto el resultado desastroso de la campaña, sino la determinación de su propia responsabilidad al respecto.

\footnotetext{
${ }^{35}$ Jean-Louis Fournel, “Du jugement de soi au tribunal de l'Histoire: I'analyse immédiate de la défaite dans les écrits de Francesco Guicciardini après le sac de Rome (1527-1530)", en Danielle Boillet y Corinne Lucas, L'Actualité et sa mise en écriture dans I'Italie des XVe-XVIIe siècles (París: CIRRI, 2005), 85-102.

${ }^{36}$ Accusatoria (París: Classiques Garnier, 2013), 244-245; traduzco: "La calamidad, la destrucción del mundo entero sólo se deben a ti y a nadie más. Por tu culpa, Hungría fue dada como presa a los infieles; por tu culpa, Roma fue saqueada con una gravísima crueldad, ocasionando una ruina inmensa, universal y particular, para tantos de nuestros conciudadanos; por tu culpa, los heréticos dominan los lugares santos; por tu culpa, han aventado a los perros las reliquias sagradas".
} 
Aquí el procedimiento de la confrontación de los puntos de vista se revela particularmente útil, pues permite que aflore el punto central de su razonamiento: al lugarteniente se le puede ciertamente reprochar un error de apreciación, pero no se le puede imputar razonablemente la suerte funesta de la Liga: ${ }^{37}$

le arme non si pigliorono né per ambizione né per altro fine che per liberarsi da questo pericolo; chi considererà, dico, queste ragione, sarà sforzato a confessare che rare volte fu per alcuno principe presa impresa né si giusta né si necessaria, né con maggiore speranza della vittoria. Né si gridava allora altro per ognuno e non manco per e' savi, che contro alla timidità ed irresoluzione del papa che pareva che andassi più lentamente che non si doveva a questa deliberazione; nella quale se lo evento è stato diverso dal giudicio, non per questo si debbe dare colpa a chi avessi consigliato la guerra, poi che le ragione erano tale che lo persuadevano a ogni savio... ${ }^{38}$

La introspección a la que se dedica el autor en estos textos, así como el análisis sistemático de los argumentos de sus detractores (basados en un discurso referido y que dejan al descubierto un desconocimiento profundo de los hechos y su encadenamiento lógico) apuntan al propósito de Guicciardini para aceptar la derrota. Con base en esta interpretación, la escritura de la historia, que permite evidenciar el enmarañamiento de las causas y consecuencias de un acontecimiento, puede ser considerada como un intento distinto de racionalización de lo ocurrido. Cuando Guicciardini regresa, años después, en el décimo octavo libro de su Historia de Italia a los acontecimientos terribles del mes de mayo, es resultado de una larga reconstrucción de la cadena de causalidades iniciada en 1494; no es, por tanto, de extrañar que en ella haga gala del espíritu de análisis que lo caracteriza y por el cual su obra ha sido alabada en numerosas ocasio-

37 Esta idea, que vuelve insistentemente en la Consolatoria, ya está presente en los "recuerdos" A136 y B160: la validez de un juicio sólo puede ser examinada tomando en cuenta las premisas que han sido evaluadas para tomar una decisión, y no en función del término de los acontecimientos.

${ }^{38}$ Consolatoria (París: Classiques Garnier, 2013), 96-99; traduzco: "no se tomaron las armas ni por ambición ni para otros fines que no fueran liberarnos de este peligro; cualquiera que, digo, considere estas razones tiene que confesar que fueron muy contadas las veces en las que alistamos, para un príncipe, una empresa más justa y más necesaria donde se tuvo la mayor esperanza de victoria. Y todos entonces, y yo entre ellos y tanto como ellos, maldecían la cortedad e irresolución del Papa que, parecía, tomaba su decisión con más detenimiento del que convenía; y si en esta decisión el resultado difirió del juicio, no por ello se tiene que inculpar a aquel que aconsejara la guerra, puesto que las razones eran tales que se imponía ésta a cualquier hombre sensato...". 
nes. ${ }^{39}$ Enumera entonces retrospectivamente las causas del fracaso, en una lista que completa y precisa sin que desaparezcan aquellas que fueron puestas de manifiesto en el momento de los hechos. Así, según el historiógrafo, Roma había sido señalada a los soldados imperiales como objetivo para saciar su codicia y garantizar su progresión en el territorio de la Liga de Cognac, y fue sacrificada para salvar Florencia. Justifica el Saco como resultado de la imposibilidad para el ejército aliado de llevar a cabo una guerra de frente (más que una guerra de asedio, lo cual llevó a seguir al enemigo, más que a adelantársele), del empecinamiento de un capitán que antepuso su propia ganancia al bienestar de Italia y del papa, de la incapacidad del propio papa para tomar las decisiones necesarias a debido tiempo ${ }^{40} \mathrm{y}$, finalmente, por los golpes que cimbraron los cimientos del gobierno florentino e impidieron al ejército de dicha ciudad reconocer con anticipación el terreno de la campaña. La toma de la Ciudad Eterna se explica además debido a la confianza ciega de Clemente VII, quien despidió a su ejército cuando el enemigo estaba en las puertas de la ciudad, a causa de la falta de discernimiento que mostró al dejar su defensa en manos de Renzo da Ceri y por la rapidez con la que el enemigo actuó para llevar a cabo sus designios. El día fatídico los soldados imperiales fueron favorecidos por la suerte (emplea en toscano la palabra "fortuna") ${ }^{41}$ y las condiciones climáticas, mientras que la muerte del condestable de Borbón, elemento inicial, dejó a los soldados privados de mando y libres de sus actos:

o diffidando, poiché alla difesa di Firenze erano condotte le forze di tutta la lega, di potere fare frutto in quella impresa, né potendo anche sostentare più l'esercito senza denari, condotto insino a quel dì per tante difficoltà con vane promesse e vane speranze, e però necessitato o a perire o a tentare fortuna, deliberò di andare improvvisamente e con somma prestezza ad assaltare la città di Roma; dove e i premi della vittoria e per Cesare e per i soldati sarebbono inestimabili, e la speranza del conseguirgli non era piccola, poi che [il papa], con cattivo consiglio, aveva licenziato prima i svizzeri e poi i fanti delle bande nere, e ricominciato sì

${ }^{39}$ Storia d'Italia, XVIII, 8, en Francesco Guicciardini, Opere (Turín: UTET, 1970), vol. 3, 1753 1760.

${ }^{40}$ Por ejemplo, el nombramiento de cardenales para reabastecer las cajas de la Santa Sede. Sobre este punto, que Guicciardini evoca en su correspondencia y retoma en Historia de Italia, remito al párrafo intitulado "Giudizi dello storico" en mi libro mencionado.

${ }^{41}$ Sobre este punto, véase la nota 24 de este artículo. 
lentamente (disperato che fu l'accordo) a provedersi che giudicava non sarebbe a tempo a raccorre presidio sufficiente. ${ }^{42}$

El ejército de la Liga de Cognac, conducido por Rangoni, llegó aquel mismo día de la entrada de las tropas imperiales a Roma pero, impotente ante lo ocurrido, renunció a intervenir, esperando una mejor ocasión que no llegaría sino hasta mucho después. Por tanto, se esforzó en evacuar hacia Orvieto al Sumo Pontífice, que había quedado encerrado en el Castillo Sant'Angelo con los más altos dignatarios de la Iglesia.

De aquí se desprende con claridad que, si bien con un ropaje más sustancioso, los elementos mencionados en la correspondencia de Guicciardini son retomados para la redacción de la Historia de Italia, a veces incluso con términos muy similares, como aparece de manera indudable en estos dos fragmentos, extraídos el primero de la carta del 13 de mayo a Silvio Passerini, ya aludida, y el segundo del libro 18 de la Historia de Italia:

et più al tardi entrorono in Roma. La quale hanno sacheggiata, factovi occisione assai, et usato ogni spetie di crudeltà et di sacrilegii, non havendo rispecto non solo a quella degnità che tucto el mondo adorava, ma né alle chiese né a Dio. ${ }^{43}$

*\%

Entrati dentro, cominciò ciascuno a discorrere tumultuosamente alla preda, non avendo rispetto non solo al nome degli amici né all'autorità e degnità de' prelati, ma eziandio a' templi a' monasteri alle reliquie onorate dal concorso di tutto il mondo, e alle cose sagre.

La misma confluencia textual se encuentra un poco más adelante en el relato historiográfico, cuando se pone de manifiesto la imposibilidad de narrar

${ }^{42}$ Guicciardini, Opere, vol. 3, 1754; traduzco: "porque todas las fuerzas de la Liga se dirigían hacia Florencia para defenderla, y dado que su ejército, que había llevado hasta allí en medio de tantas emboscadas echando mano de vanas promesas y de esperanzas infundadas, ya no podía alimentarse sin dinero, Carlos de Borbón, obligado a perecer o a tentar a su suerte, decidió ir por sorpresa, y lo más rápido que podía, atacar la ciudad de Roma, donde los frutos de la victoria no serían pocos puesto que el Papa había imprudentemente despedido a los suizos y después de ellos a los infantes de las Bandas Negras, y después había reanudado con tal lentitud sus preparativos (cuando ya había desaparecido toda esperanza de paz) que el Borbón juzgó que él [el Papa] no podría reunir oportunamente suficientes fuerzas...".

${ }^{43}$ (Carteggi, 27). 
los hechos (Però sarebbe impossibile non solo narrare ma quasi immaginarsi le calamità di quella città; Impossibile a narrare la grandezza della preda), ${ }^{44}$ que hace eco a una carta del 15 de mayo a los Ocho de Práctica (De' danni et ribalderie facte in Roma et della preda inestimabile che hanno facta non si potrebbe dire tanto che non sia decto molto più). ${ }^{45}$ Una de las explicaciones de estas similitudes reside sin duda alguna en el hecho de que cuando emprende explícitamente un regreso a las fuentes para redactar su Historia, Guicciardini consulta, entre otras, las cartas que redactó durante su misión como lugarteniente. ${ }^{46}$

Sin embargo, cabe observar que Guicciardini distingue, en su monumental historia, entre dos tipos de integrantes de la infantería enemiga, algo menos evidente en el carteggio. Por un lado los españoles quienes, apostados en el Trastévere, dejados sin órdenes ni noticias de la otra parte del contingente, deciden penetrar en la ciudad por el Puente Sixto y no muestran respeto por el nombre y la dignidad de los prelados ni por los templos, conventos y reliquias, a tal punto que Guicciardini los compara con los godos, aquellos bárbaros que saquearon la ciudad en el año 410. ${ }^{47}$ A estas fechorías se añade el robo de las riquezas romanas, cuyo valor era incalculable (Guicciardini habla de más de un millón de ducados, a los cuales se puede añadir el dinero de los rescates posteriores de numerosos personajes que habían sido puestos en cautiverio). ${ }^{48}$

Del otro lado están los alemanes, luteranos, que se oponen a la iglesia romana y sobresalen por su barbarie, particularmente en lo relativo a los objetos del culto; añadieron a estas fechorías crueldad e insolencia, obligando a los prelados a recorrer la ciudad montados en animales viles, lo cual, por la vergüenza

\footnotetext{
${ }^{44}$ Guicciardini, Opere, 1758.

${ }^{45}$ (Carteggi, 33).

${ }^{46}$ Paola Moreno demostró que en los meses que preceden el Saco, Guicciardini hizo realizar por su secretario una copia de trabajo de sus cartas -copialettere en italiano- del 8 de junio de 1526 al 18 de febrero de 1527, de la cual se sirvió para redactar los libros 16 y 17 de la Historia. Moreno, "Il carteggio guicciardiniano, fabbrica della Storia d'Italia", en La "Storia d'Italia" di Guicciardini e la sua fortuna (Milán: Cisalpino, 2012), 67-87 y Moreno, "Quando l'autore corregge se stesso. II caso unico del copialettere di Francesco Guicciardini", en Epistolari dal Due al Seicento. Modelli, questioni ecdotiche, edizioni, cantieri aperti. Atti del XVI Convegno internazionale di letteratura italiana "Gennaro Barbarisi" (Gargnano del Garda 29-30 de septiembre - 1 de octubre de 2014), en prensa.

${ }^{47}$ Guicciardini, Opere, vol. 3, 1758.

48 "Ed era fama che, tra denari oro argento e gioie, fusse asceso il sacco a più di uno milione di ducati, ma che di taglie avessino cavata ancora quantità molto maggiore" (Guicciardini, ibid., 1759).
} 
que les provocó, acortó sus vidas. ${ }^{49}$ En su correspondencia, en cambio, Guicciardini retoma este último acto atribuyéndoselo nada más a los españoles: "Sono prigioni la Valle, Cesarino et Araceli. Et questo fu condocto pubblicamente in su uno asino dove piacque a certi Spagnoli che l'avevano preso"..$^{50}$ Esta larga lista de calamidades se ve aún aumentada por los daños materiales: destrucción de los palacios de prelados y ricos y -mientras los españoles solían mostrar cierto grado de piedad a cambio de sumas de dinero significativas- los alemanes, que pasaban después de ellos, daban muestras de máxima crueldad al no dejar en pie ningún palacio o exigiendo para perdonarlo un segundo monto de rescate. No hacían excepción con nadie, incluso quienes por tradición se habían sumado a las fuerzas del emperador (como, entre otros, los Colonna). Y finalmente sigue la descripción de los malos tratos infligidos a las mujeres.

Esta última evocación del Saco de Roma es la del hombre de acción que, después del negozio, ve que toma forma el ozio e intenta relatar los acontecimientos terribles de los cuales ha sido a la vez actor y espectador, es decir, según sus propios términos, "una llama y una peste que no sólo transformó los estados, sino también los modos de gobernarlos y de guerrear", ${ }^{51}$ cuando Italia tenía a "dos aves de presa en sus entrañas". ${ }^{52}$ Resulta interesante que la descripción que da Guicciardini del Saco con la distancia de la reflexión, aunque más completa, no deja de coincidir con el análisis fino de las causas y consecuencias que entregó en vísperas y en los días inmediatamente posteriores a los hechos.

\footnotetext{
49 "Tutte le cose sacre, i sacramenti e le reliquie de' santi, delle quali erano piene tutte le chiese, spogliate de' loro ornamenti, erano gittate per terra; aggiugnendovi la barbarie tedesca infiniti vilipendi" (Guicciardini, ibid.) y "molti prelati presi da' soldati, massime da' fanti tedeschi, che per odio del nome della Chiesa romana erano crudeli e insolenti, erano in su bestie vili, con gli abiti e con le insegne delle loro dignità, menati a torno con grandissimo vilipendio per tutta Roma" (Guicciardini, ibid., 1758).

50 "La Valle, Cesarino y Araceli son prisioneros. Y éste fue llevado públicamente a lomo de burro hacia donde les plugo a unos españoles que lo habían agarrado" (carteggi, 27). 51 "E era entrata in Italia una fiamma e una peste che non solo mutò gli stati, ma e' modi ancora del governargli e e' modi delle guerre..." (Storie fiorentine, en Guicciardini, Opere, vol. 1, 117).

52 "considerando con quanta fatica al tempo che in Italia non erano prìncipi esterni si difendeva la commune libertà, ora quanto più sarà difficile, avendo sì grandi uccelli nelle viscere sue..." (Discorso di Logrogno, en Guicciardini, ibid., 249).
} 
La (più) terribile tragedia che si sentisse mai ${ }^{53}$ Marino Sanudo y los Diarii

El caso de los Diarii de Marino Sanudo (1466-1536) es muy distinto. Sanudo o Sanuto, apodado "el joven" -para distinguirlo de su homónimo Marino Sanudo Torcello, llamado "el viejo" - era un patricio veneciano y hombre de letras que da cuenta de los acontecimientos presenciados, esperando ser considerado algún día para el puesto de historiógrafo oficial de la República de Venecia. Elabora un inventario minucioso de las cosas que ocurrieron en Italia y fuera del país, insertando en su texto materiales muy dispares tanto de índole oral como escritos, que recopila para este fin. Toma así nota de diversas cartas y, por medio de ellas, de las decisiones que vehiculan. ${ }^{54}$ Conforman sus Diarii 56 volúmenes que cubren el periodo de enero de 1496 a septiembre de 1533 y proporcionan un informativo reporte de los acontecimientos que tuvieron lugar durante su vida, desde el más insignificante, a veces incluso de índole casi privada, hasta las decisiones más relevantes de política interior y exterior, a lo cual se añaden numerosos detalles de la vida diaria en Venecia, así como algunos juicios muy personales.

En 1531 Sanudo obtiene de la República una renta de 150 ducados por mes y acceso a los archivos secretos de la Serenísima, con el compromiso depermitir a Pietro Bembo, recientemente designado para el puesto que Marino codiciaba, la compulsa y utilización de sus notas. ${ }^{55}$ Este acceso privilegiado que Sanudo tuvo a los documentos secretos de Venecia confiere a su trabajo un carácter único; el mismo Bembo dirá de los Diarii que contienen "mucho material muy útil, tanto como información superflua". ${ }^{6}$ Según Guiglielmo Berchet, quien redactó el prólogo de la edición más reciente de los Diarii, es

la inagotable riqueza y la infinita variedad de los detalles que allí se narran la que hace de los Diarii una pintura viva, verídica, real, palpitante de su tiempo [...]; el

\footnotetext{
${ }^{53}$ Diarii, 163: "La más terrible tragedia que se haya referido jamás".

${ }^{54}$ Así se descubrió hace poco que algunas cartas de Guicciardini habían sido reproducidas casi tal cual por Sanudo en sus Diarii; aún no han sido tomadas en consideración para una edición distinta.

${ }^{55}$ Véase al respecto Marie-Françoise Viallon-Schoneveld, "Infortune e fortune d'un historiographe vénitien: Marin Sanudo", en L'Histoire et les historiens au XVle siècle. Actes du VIlle colloque du Puy-en-Velay (Saint-Étienne: Publications de l'Université de Saint-Étienne, 2001), 27-42, consultado el 16 de noviembre de 2017, http://hal.archives-ouvertes.fr/ docs/00/15/88/62/PDF/Marino_Sanudo.pdf.

${ }^{56}$ Robert Finlay, "Politics and History in the Diary of Marino Sanuto", Renaissance Quarterly 33, núm. 4 (1980): 585-598, cita en 589.
} 
hilo de la historia se desprende de las noticias que se suceden con el transcurrir de los días, pero es una historia viva e inspiradora que se deduce de los documentos diplomáticos y de las cartas confidenciales, de las conversaciones de los príncipes, de los discursos del Senado, de las voces del pueblo, de anécdotas, de sátiras, todo ello reunido con máximo cuidado. ${ }^{57}$

Material muy variado, pues, testimonio privilegiado de la reticularidad de la información veneciana y polifónica por naturaleza, puesto que Sanudo se borra ante los personajes -cualquiera que sea su rango- de los cuales da a leer los textos e intervenciones. El análisis que aquí propongo no puede de ninguna forma apartarse de este punto de partida, que constituye la esencia misma del trabajo de Sanudo. ${ }^{58}$

Si Guicciardini, en sus cartas, no es nada prolijo acerca del Saco, no pasa lo mismo con Sanudo, quien le dedica la casi totalidad del tomo 45 de sus escritos, en el cual los acontecimientos romanos son descritos unas veces de modo anecdótico, otras en un relato atiborrado de detalles. Así, "durante dos semanas en mayo de 1527, Sanudo transcribió 42 cartas recibidas de 13 corresponsales acerca del espantoso saqueo de Roma por las tropas imperiales". ${ }^{59}$ Como en las cartas de Guicciardini, los días iniciales del mes de mayo se ven copados por las negociaciones llevadas a cabo para el ingreso de Florencia en la Liga de Cognac y Sanuto, del mismo modo que relata con precisión los puntos tratados por el Senado veneciano, no deja de describir las intervenciones de cada uno de los participantes presentes para el cierre del acuerdo, incluyendo a Francesco Guicciardini. El veneciano igualmente da cuenta de todos los desplazamientos decididos por los dirigentes de la Liga, con lo cual corrobora los hechos referidos por el historiógrafo florentino. Empero, y sin aviso explícito, estas descripciones ceden paso al relato de las "cosas de Roma" y a la información

\footnotetext{
${ }^{57}$ Guglielmo Berchet, Prefazione ai Diarii di Marino Sanudo (Venecia: Istituto Veneziano per la Storia Patria, 1902), 133-134; la traducción es mía.

${ }^{58}$ Acerca de la información y redes de comunicación en Venecia por medio de los tres canales que son el manuscrito, el impreso y la oralidad, es imprescindible la consulta de los trabajo de Filippo de Vivo: Information and Communication in Venice. Rethinking Early Modern Politics (Oxford: Oxford University Press, 2007) y Patrizi, informatori, Barbieri, política e comunicazione a Venezia nella prima età moderna (Milán: Feltrinelli, 2012).

${ }^{59}$ Finlay, "Politics and History in the Diary...", 589; la traducción es mía. Es preciso acotar que estos documentos fueron recientemente reunidos por Danilo Romei, Diari del sacco di Roma di Marin Sanudo ([s. I.]: Lulu, 2016), en un volumen publicado a cuenta del autor, integralmente disponible en línea, consultado el 15 de septiembre de 2017, http://www. nuovorinascimento.org/n-rinasc/testi/pdf/sacco/sanudo_nr.pdf.
} 
que circula al respecto: "La mattina tutta la terra fù piena di tal nove di Roma, chi la credeva et chi non, et maxime fin nona non esser venuto alcun avixo; di che tutti se meravegiava" (Diarii, 77). ${ }^{60}$

Sanudo incluso no repara en manifestar la divergencia de opiniones del Colegio y de los Diez en cuanto a la veracidad de los hechos; de ahí surge que incluso en las más altas instancias del poder veneciano se complicaba el establecimiento de un diagnóstico expedito y una ponderación justa entre los rumores y las informaciones veraces:

Et non essendo nulla di novo, a tutti pareva gran cosa, ogniun diceva la soa; io sempre d'opinion che la cosa era vera. Et vene una voce esser lettere. Fo mandato per la Signoria Lorenzo Roca secretario dal Serenissimo per saper, qual tornato, referì esser aviso di l'orator di Fiorenza ha per uno partì di Pexaro a di 10, con nove vechie; siché tutti restono confusi. Et disciolto il Conseio apena, vene voce inimici esser intrati in Roma, morto il duca di Borbon et taià a pezi più di 4000 de inimici. Et questo era per lettere del Proveditor Pixani... (Diarii, 86). ${ }^{61}$

El mismo Sanudo vacila en cuanto al crédito que es oportuno dar a los relatos que transcribe. De entrada, en vez de sumarse a una versión o seleccionar la información pertinente, el veneciano confronta todos los rumores, todas las voces que tenderían a confirmar o desmentir la noticia que acababa de llegarle. En este proceso de selección deja lugar a la duda y expresa, por este mismo hecho, el ambiente de angustia y curiosidad que debía reinar en Venecia ante el anuncio de un acontecimiento de tal importancia simbólica: la toma rápida de Roma suscitó estupor y asombro, lo cual hizo que durante cierto tiempo los habitantes de la ciudad lacustre se sintieran incapaces de tomar posición frente

\footnotetext{
${ }^{60}$ Traduzco: "Por la mañana, todo el mundo se llenó de tal noticia acerca de Roma, algunos la creían, otros no, sobre todo porque a la novena hora no había llegado ninguna información oficial; de lo cual todos se maravillaban".

${ }^{61}$ "Y como no había noticias, esto parecía a todos algo de maravillarse, y cada uno emitía su propia explicación; y yo siempre pensé que la cosa era verdadera. Y entonces llegó una voz anunciando que había correo. Lorenzo Roco, secretario del Serenísimo, fue enviado por la Señoría para saber, y éste, cuando volvió, refirió que había un mensaje del orador de Florencia recibido por parte de un hombre que abandonó Pesaro el 10 con noticias viejas, así que todos permanecieron confundidos. El 18, apenas iniciadas las labores del Consejo, llegó alguien [para dar aviso de] que los enemigos habían entrado a Roma, [que había] muerto el duque de Borbón y que más de 4,000 enemigos habían sido hechos añicos. Y esto provenía de una carta del Proveedor Pisani".
} 
a los hechos que les eran relatados. Una carta del Proveedor Pisani, que Marino Sanudo reproduce en sus Diarii, parece frenar en seco las vacilaciones:

avisa come a di 6 inimici in Borgo erano presentati, et era stà gran difesa et morto il duca di Barbon di uno arcobuso nel peteneio, et di loro da numero 4000, i quali erano intrati. El Papa è redutto in castello con li cardinali. Sichè vadino presto per soccorrer Soa Santità. Poi scrive esso zerca danari, et caminavano avanti (Diarii, $86-87) \cdot{ }^{62}$

\section{$[\ldots]$}

Scrive esser venuto uno fratello da Lenso da Perosa contestabile nostro, qual parti da Roma a dì 7. Referisse inimici esser entrati in Roma per il Borgo del castello per Belveder, et sachizavano Roma, brussando etc. II Papa era intrato in castello con li cardinali, excepto do, il cardinal Valle et Cesarin, i quali sono di la fazion Colonese, et li oratori, tra li quali il cardinal Pixani suo fiol. Et haver visto portar morto da tre archibusate il duca di Barbon, et tuttavia sachizavano Roma, mettendo foco in molte case" (Diarii, 87). ${ }^{63}$

Mientras que la transcripción de esta misiva podría dejar pensar que se acabó el debate acerca de la veracidad de la toma de Roma, Sanudo transcribe otro fragmento del que toma conocimiento el día 12 de mayo: cuando el Señor Baldissera preguntó al mensajero del duque de Urbano si era cierto que los españoles habían entrado a Roma, le dijo que no. ${ }^{64}$

62 Traduzco: "Él [es decir, Pisani] avisa que el día 6 enemigos estaban presentes en el Borgo y que ya se había llevado a cabo un combate de defensa y [que había] muerto el duque de Borbón de un arcabuzazo en el pecho, y que 4,000 enemigos habían entrado. El papa está encerrado en el castillo con sus cardenales. De tal forma que se apresuran para brindar ayuda al papa. Después, este Proveedor escribe acerca del dinero y dice que están adelantando".

${ }^{63}$ Traduzco: "Escribe que un hermano de Lenzo de Perugia, uno de nuestros condestables, vino después de dejar Roma el día 7. Relata que los enemigos habían entrado a Roma por el Borgo del Castello y por el Belvedere y estaban saqueando Roma, quemando, etc. El papa había entrado al castillo con los cardenales, excepto dos, los cardenales Valle y Cesarino, de la facción de los Colonna, y los oradores, entre los cuales el cardenal Pisani, su hijo. [Dice] haber visto al duque de Borbón muerto de tres arcabuzazos y que continúan saqueando Roma, incendiando numerosas casas".

64 "Depositione del reverendo domino Baldissera da Pescia circa le cose di Roma, habuta a dì 12 di mazo 1527. È venuto in questa città il reverendo missier Baldissera da Pescia prelato degnissimo di fede, il quale narra, che hier mattina a li 11 in su l'alba, essendo sbarcato la sera dinanzi al porto di Cervia, et passeggiando in su ditto porto, passò uno in posta che diceva essere huomo d'arme del signor Malatesta Baglion, et che veniva dalla excellentia 
Al principio Sanudo recibe información de la caída de la Ciudad Eterna sin más detalles, lo cual le deja el campo libre para relatar las exacciones cometidas también por los soldados aliados, de lo cual Guicciardini no hacía eco. Esta elección denota una voluntad de describir los hechos sin concesión alguna hacia sus protagonistas ni intención de transmitir una verdad oficial de cualquier tipo. De este modo, menciona las exacciones del ejército de la Liga de Cognac -grisones y suizos, franceses guiados por Michel-Antoine de Saluces, italianos de Juan de las Bandas Negras-, que considera no menos crueles que las que serían infligidas al pueblo romano:

Li capitani di francesi sono la più parte mantoani, zoveni che non pensano se non robar. Di loro non potria scriver ben niuno, et sono malissimo pagati. De li fanti de la Chiesia et fiorentini, io non li ho visti, per esser aviati alla volta di Roma; ma pur ho inteso la verità. Quelli fo del signor Zanin di Médici, che si chiama la Banda negra, sono da 2500 et più tosto manco, et sono pezo che turchi. Hanno sachizato in Valdarno tre castelli de fiorentini, et forzato femene et fatto altre cose crudelissime (Diarii, 75). ${ }^{65}$

Una de las cualidades innegables de Sanudo es que no parece partir de ninguna idea preconcebida. En efecto, si bien el veneciano no vacila en dar cuenta de los hechos imputables a las tropas aliadas de la Liga, tampoco se abstiene de atestiguar los actos de crueldad de los enemigos, siempre y cuando tenga acceso a los hechos. Las informaciones ocupan su lugar en los diarios de Sanudo en el orden en el que van llegando a Venecia y el patricio toma conocimiento de ellas. Si el orden cronológico suele ser el eje rector de la organización del material bruto, en el caso del Saco de Roma que aquí nos interesa se suceden informaciones nuevas y noticias que ya tienen algunos días. Se vislumbra que Sanudo persigue la exhaustividad sin prestar demasiada atención a la calidad

del signor duca di Urbino, mandato dal signor Malatesta a Padova; et domandandolo il ditto missier Baldissera se era vero che li spagnoli fussero entrati in Roma, gli disse di no, et che a li 10 si era partito dalla excellentia del duca..." (Diarii, 87).

${ }^{65}$ Traduzco: "Los capitanes de los franceses son en su gran mayoría mantuanos, jóvenes que sólo piensan en robar. De ellos nadie nunca podrá escribir nada bueno, y les pagan muy mal. A los soldados de la Iglesia y a los florentinos no los he visto porque están marchando hacia Roma; pero sí he escuchado la verdad: aquellos son tropa del Señor Juan de Médici, que se llama Banda Negra, máximo unos 2,500 hombres, y son peores que los turcos. Saquearon tres castillos de florentinos en Val d'Arno y forzaron a mujeres, además de otras cosas muy crueles". 
de la información, a las repeticiones o contradicciones. Resulta interesante observar que ningún comentario del autor acompaña los documentos transcritos.

Los detalles referidos por Sanudo corroboran varias veces el relato de Guicciardini. Entre éstos no puede dejar de mencionarse la alusión al valor del pueblo romano, cuando afirma que "el pueblo estaba decidido a compartir la suerte de Nuestro Señor, tomando las armas y la defensa de su Beatitud y de la ciudad, por voluntad propia".66

El 10 de mayo Venecia divulga por fin la noticia de la toma de Roma, entre otras razones para acelerar la provisión, poniendo fin a la incertidumbre. El día 11, el Colegio debate con vehemencia acerca de la liberación del papa y el Consejo de los Diez decide brindarle auxilio. Sanudo toma nota de forma resumida -al contrario de lo que acostumbra- de varias cartas que dan cuenta de los sinsabores de Roma, lo cual permite imaginar la abundancia de noticias que estaban Ilegando a Venecia:

Summarii di lettere venute di la nova di Roma, in lettere del secretario Rosso da Suggillo, a lì 10 Mazo, a hore 24. Alcuni fuziti da quella misera città di Roma, partiti il Marti avanti dì, a dì 7, affirmava il Papa esser in castello con quasi tutti li cardinali et oratori. Li inimici tutti esser intrati in Roma, sachegiando, et amazando senza perdonar né a donne né a puti, et brusavano qualche caxa. Et che nel suo ingresso et da poi ne sono stà morti cerca 4000. Affermano la morte del signor Camillo et del figlio del signor Renzo; de lui, non sapersi altro. El signor Orazio Bagion esser in castello. Barbon morto de uno arcobuso. Et esser tanta la confusion tra soldati, che se l'exercito de la liga arrivasse presto, se ruineriano l'inimici (Diarii, 90). ${ }^{67}$

\footnotetext{
66 "Questo cavallaro referisse a boca, che Nostro Signore avea già adunato grosso numero di fanteria, et quella distribuita in Borgo, in Trastevere, in Santo Janni, et ad altri luoghi apti alle custodie di Roma, et che il popolo era deliberato voler correre una medesima fortuna con Nostro Signore, pigliando animosamente le arme a difesa di Sua Beatitudine et della città et de lor medesimi" (Diarii, 76).

${ }^{67}$ Traduzco: "Resúmenes de las cartas que llegaron acerca de las noticias romanas, entre las cartas del secretario Rosso da Suggilio, el 10 de mayo a las 21 horas. Algunos fugitivos de esta pobre ciudad de Roma que salieron el martes antes del amanecer, el 7, afirmaban que el Papa estaba en el castillo con casi todos sus cardenales y oradores. Todos los enemigos ya habían entrado a Roma, saqueando y matando sin perdonar ni a las mujeres, ni a los niños, y quemando algunas casas. Durante el asalto y después murieron alrededor de 4,000 hombres. Afirman que murieron el Señor Camillo y los hijos del Señor Renzo, y dicen no saber nada más. El Señor Orazio Bagioni está en el castillo. Borbón muerto de un arcabuzazo. Y que hay tanta confusión entre los soldados que si el ejército de la Liga llegara pronto acabaría con los enemigos".
} 
Non si verifica la morte di Borbone, et non si crede, et dicono fu fatta quella fama per dare animo a questo exercito che si facesseno avanti, pensando che privi del capitanio havessino ad pensare poterli più facilmente rompere et trovare in disordine (Diarii, 123). ${ }^{68}$

Donde Guicciardini sintetizaba la información e iba directo al grano, es decir, la estrategia militar que se debía adoptar, Sanudo, como reportero de su tiempo, da cuenta pormenorizada sobre los actos de crueldad cometidos por los enemigos, a los cuales añade un resumen de su propio cuño. En la misma óptica, al infausto destino del Borbón y al encarcelamiento del papa y los cardenales añade el detalle de los malos tratos a los que fueron sometidas las mujeres romanas. Y es aquí donde se encuentra el verdadero nudo de la escritura de Sanudo: lejos de narrar una historia, la Historia, el autor se entrega por completo a un trabajo de redacción de memorias que lo lleva a consignar la totalidad de las informaciones recogidas y justifica que se dé lugar a un rumor infundado como una opinión que desmiente la muerte de Carlos de Borbón. Mientras que Guicciardini, sin duda confiado en la calidad de sus fuentes, da cuenta de la muerte del condestable francés en cuanto se entera de ella, preocupándose exclusivamente por la organización de las tropas imperiales privadas de su mando, Sanudo transcribe miles de versiones de la muerte del traidor y de su entierro, no sin haber dudado -durante un lapso breve-de la veracidad de dicha defunción. En efecto, según los datos consignados sobre este hecho en los Diarii resulta que Carlos de Borbón murió en algunos casos de un solo arcabuzazo en el pecho, en otros después de una salva múltiple que le desgarró el muslo y explotó sus intestinos, en otros más solamente había muerto debido al rumor al servicio de los poderosos.

Tales hechos en la presentación de las informaciones consignadas le valieron a Sanudo el calificativo de "reportero" y justifican que se haya puesto de manifiesto el carácter pintoresco y naturalista ${ }^{69}$ de su crónica: no se encuentra en ella

\footnotetext{
${ }^{68}$ Traduzco: "No se da testimonio seguro de la muerte de [Carlos de] Borbón, y no se cree del todo cierta, y se dice que este rumor fue creado para infundir ánimo a este ejército para que avanzara, pensando que, privados de su capitán, juzgaría poder derrotarlos más fácilmente y ponerlos en desbandada".

${ }^{69}$ Viallon-Schoneveld dice al respecto que "comme un reporter moderne, il a un grand appétit d'informations 'de première main' qu'il accumule sans chercher à les organiser, ni à les hiérarchiser, ni à les synthétiser" ("Infortune e fortune d'un historiographe vénitien...", 29); "In tali pubblicazioni [es decir, de misceláneas que tratan de un tema o una región en particular] è d'uopo sacrificare del tutto quella forma rozza, se vuolsi, ma ingenua e
} 
ningún intento de explicar las causas y consecuencias del Saco, ningún análisis ni puesta en perspectiva, ninguna conclusión que se pudiera sacar de la confrontación de las fuentes, sólo una colección de informaciones destinada a ofrecer una vista en conjunto de los acontecimientos, una fotografía de la palabra y la escritura en Venecia, en un momento preciso y alrededor de un tema específico.

Por último, cabe destacar en los Diarii de Sanudo la abundancia de relatos que denuncian las exacciones de las tropas imperiales -a las que suele referirse como "los españoles"- y la insistencia con la que el cronista reproduce los documentos que atestiguan saqueos, masacres y atrocidades cometidas en contra de la Iglesia, sus prelados y, más aún, las reliquias cristianas. La amplia acogida que hizo a los documentos que atestiguan estos actos anti heroicos debe ser revisada en la perspectiva antiespañola predominante en Venecia ${ }^{70}$ dando como característica general para los Diarii la acumulación de testimonios destinados a desacreditar a los imperiales. El relato hecho por un fraile de San Pietro in Vincoli al Dogo y referido por Sanudo es un ejemplo clarísimo de ello: ${ }^{71}$

Che intrati inimici in Roma la comenzono a sachizar, et quelli si defendevano nelli palazzi et caxe, poi presi erano tutti taiati a pezi, usando contro di loro grandissima crudeltà, et li puti morti li butavano fuora di le porte su la strada, et le done erano strasinate et menate per la terra, dico di le principal, da zente vilissima et altri, con grandissimi pianti et ululati che si sentiva per la città [...].

Che tutti hanno atteso a far butini, et è stà grandissimo saco con gran strage, et esser stà morti da 14 in 15 milia, et de inimici da 3 in 4000, secondo il suo iuditio.

pittoresca che è propria del nostro Autore, e che non solo persuade la verità della storia, ma è storia anch'essa; conviene inoltre, ed è più grave discapito, togliere pur qualche cosa alla integrità piena delle notizie, le quali essendo già date dal cronista in modo sommario, non possono essere riassunte che a detrimento della loro pienezza" (Berchet, Prefazione ai Diarii..., 146) o bien "Chi ama il verismo nella storia non può trovare uno specchio migliore di questi Diarii" (ibid., 133-134).

70 Marie-France Piéjus, "La destruction fondatrice: le prologue des Hecatommiti de Giraldi Cinzio (1565)", en Redondo, Les discours sur le sac de Rome..., 137-150.

71 "Relatione di uno frate di S. Piero in Vincula di Roma, di l'ordine di frati di San Salvador, il qual partì di Roma adi 12 Magio 1527, fatta in camera del Serenissimo a dì 20 ditto a hore 1 di notte. Il frate è nominato fra Angelo Maria da Orvieto" (Diarii, 65). Sanudo tuvo acceso a numerosos informes redactados en algunos casos por diplomáticos y gestores venecianos ("oratori", "provveditori"), en otros por ciudadanos que escriben con carácter privado, otras veces por miembros del clero romano cuyo relato llegó hasta la Serenísima o aun bajo la forma de intercambios entre Eleonora Gonzaga, duquesa de Urbino y los campos militares donde se despliegan las tropas de su esposo. Para descripciones similares recibidas por la duquesa de Urbino, véanse los Diarii, 165-167 y 183-190. 
Che li butini loro li redusevano in Borgo tenendo lì esser più sicuri che in Roma, et continue sachizavano, usando grandissima crudeltà, maxime contra preti et frati.

Che del suo monastero di S. Piero in Vincula, hanno sachizato tra arzenti el paramenti et altro per la valuta di scudi 30 milia.

Che hanno aperti et roti li monasteri di monache Observante et quelle vergognade, imo roto muri dove stavano done santissime richiuse, et quelle menavano per Roma vergognosamente.

Che uno crocefixo d'arzento era in la chiesia di S. Piero, li hanno dato et rotto in 4 parte, et a uno S. Pietro datoli 3 ferite.

Che la capella di S. Piero era fatta stalla di cavalli, nè hanno alcuna religion, nè timor di Dio.

Che hanno brusadi do bei palazi in Roma, quello del reverendissimo cardinal di Como, et quel del signor Renzo, oltra altre case... ${ }^{72}$

No obstante, como en el caso de Guicciardini, quien dice preocuparse por la "salvación del mundo y de la fe cristiana oprimida por estos herejes", ${ }^{73}$ se opera

72 "Que una vez que los enemigos entraron a Roma empezaron a saquear la ciudad, y aquellos se defendían en los palacios y las casas, pues todos eran capturados y cortados en pedazos, empleando contra ellos una crueldad sin medida, echaban por las puertas a las calles los cadáveres de los niños, las mujeres eran laceradas y arrastradas por el piso, hablo de mujeres de alto rango, por gente vil y de toda índole, en medio de grandes llantos y aullidos que se escuchaban por toda la ciudad [...].

Que todos esperaron para hacerse de un botín importante y hay un gran saqueo con matanzas muy graves, y que han muerto 14 a 15 mil personas, y de enemigos 3 a 4,000, según su estimación.

Que llevaban su botín al Borgo, pensando que estaban allí más a salvo que en Roma, y saqueaban sin cesar, haciendo uso de una gran crueldad sobre todo para con los sacerdotes $y$ frailes.

Que de su monasterio de San Pedro Encadenado, saquearon tres dineros y adornos y otras cosas por un valor de treinta mil escudos.

Que abrieron y destruyeron los conventos de las hermanas practicantes y avergonzado a éstas, destruyeron paredes tras las cuales se encontraban encerradas damas muy santas y arrastraron a éstas de forma muy deshonrosa por toda la ciudad de Roma.

Que un crucifijo de plata estaba en la iglesia de San Pedro y se lo dieron partido en cuatro, y a uno de San Pedro le infligieron tres heridas.

Que la capilla de San Pedro ha sido transformada en establo para sus caballos, pues no tienen ninguna religión ni temor a Dios.

Que quemaron dos hermosos palacios en Roma, el del reverendísimo cardenal de Cosme y el del señor Renzo, además de otras casas".

73 "In modo che, dove prima si tractava della libertà della povera Italia, si combacte hora della salute del mondo et della fede di Cristo, conculcata da questi heretici" (carteggi, 68). 
una distinción entre los distintos cuerpos que componen el ejército imperial, y la oposición a la fe cristiana de los lansquenetes no puede más que acentuar sus fechorías. Esta gradación traiciona la representación que hacían los contemporáneos de esos soldados luteranos que viajaron a Italia buscando saciar su afán de lucro. Estas diferencias de comportamiento entre los miembros del ejército imperial parecerían, de hecho, ser causa de disensión interna: "Dice che, per certo lanzchenechi amazorono tutti li frati et preti, et dolendosi spagnoli, dicendo essere homeni da taglie, risposero havere promesso a Dio amazzarli tutti che veranno alle loro mani et non cavare da loro taglie" (Diarii, 122). ${ }^{74}$

De los escritos analizados emerge la descripción de un enemigo común: el ejército imperial, autor de fechorías de las que los coetáneos hablaron durante mucho tiempo, como lo relata Sanudo, y acerca de lo cual corrió mucha tinta. Aunque llamados genéricamente españoles cuando se habla de los adversarios, se puede observar una distinción entre naciones cuando se mencionan las acciones llevadas a cabo: cristianos, los españoles no son culpables de crímenes en contra de la Iglesia, pero se dejan llevar por la sed de oro y plata, mientras que las acciones sacrílegas y los asesinatos de miembros del clero y profanaciones sólo pueden ser obra de lansquenetes luteranos. Esta apreciación no es enteramente compartida -o por lo menos explícitamente expresada- por Guicciardini en su correspondencia, pero terminará sumándose a ella en su Historia de Italia, tal vez influido por los numerosos relatos sobre el Saco que circularon en el lapso que medió entre los acontecimientos y su obra historiográfica posterior, en los cuales esta dicotomía se percibe con nitidez. ${ }^{75}$

\section{Io ho deliberato di scrivere le cose accadute alla memoria nostra \\ Conclusiones}

El carteggio de Guicciardini y los Diarii de Sanudo presentan la particularidad de ser testimonios en contacto directo con los acontecimientos que vivieron sus autores; permiten apreciar sin ninguna mediación, y al lado de cualquier proceso

\footnotetext{
74 "Se dice que es una certeza que los lansquenetes mataron a todos los frailes y sacerdotes, de lo cual se quejaron los españoles diciendo que eran hombres que buscaban sacar dinero de los cautivos, [a lo cual] respondieron que habían prometido a Dios matar a todos aquellos que cayeran en sus manos sin pedir rescate".

${ }^{75}$ Véase al respecto Ponsiglione, La "Ruina" di Roma....
} 
de codificación o sedimentación literaria, ${ }^{76}$ el impacto sobre dos contemporáneos de un periodo histórico particularmente catastrófico.

Sin embargo, muchos son los puntos de divergencia entre estos hombres que escriben: su origen, capacidad y, por ende, su grado de implicación en el desastre romano. La función que otorgan a la escritura en el momento en el que se dan los hechos también los distingue, así como la diversidad de sus intereses, que los lleva a resultados muy distintos. Guicciardini, cuando redacta sus cartas, actúa en un contexto de urgencia y en pos del bien común, intenta discernir los problemas lo antes posible para anticipar las repercusiones concretas; lleva a cabo un análisis que debe orientar las decisiones prácticas. En tales circunstancias, no puede dar rienda suelta a sus lamentaciones sobre la masacre de Roma. Sanudo, por su parte, no es más que un espectador ilustrado y particularmente bien informado. En su calidad de observador interesado por los acontecimientos de su tiempo, registra minuciosamente las informaciones e intenta, amplificándolas, acercarse lo más que puede a la realidad. Sobre este último punto ambos escritores convergen, dado que Guicciardini a posteriori se dejará guiar por esta misma intención cuando intenta recordar el camino que llevó a la pérdida de autonomía de los estados italianos.

Del mismo modo se puede afirmar que los autores tienen métodos menos divergentes de lo que parecería en un principio. La "verdad" que pretenden restablecer se funde en el cruce de las fuentes. Es cierto para Guicciardini en el momento mismo de los hechos, y lo sigue siendo cuando se pone a redactar su gran fresco de las guerras de Italia. Se deja llevar entonces por una forma de prospección documental metódica tanto en los archivos florentinos como en sus propios escritos epistolares, de los que puede seguir la huella, en filigrana, en las páginas de la Historia (en lo que respecta a las palabras empleadas y en los juicios expresados, del todo coherentes con los primeros análisis entregados por el autor al calor del momento).

Las motivaciones de ambos autores, así como los resultados que alcanzan, difieren sin embargo, y el estudio en conjunto de los numerosos escritos de Guicciardini sobre el Saco de Roma (cartas, oraciones e historiografía) vuelve la brecha que los separa particularmente evidente. En Sanudo -motivado por su ambición de acceder a un cargo que se le escapa- la recopilación de infor-

${ }^{76}$ Como bien lo observa Ponsiglione, traduzco: "el objeto real, el referente histórico (es decir los acontecimientos tardíos relativos a la ocupación y el saqueo de Roma) se transforma [...] muy rápidamente en 'texto', es decir, en una codificación específica y peculiar del mismo" (ibid., 19). 
maciones nunca cede el lugar a una interpretación o narración, dado que se conforma con registrar los hechos. Para Guicciardini, en cambio, la puesta en perspectiva del carteggio con los escritos posteriores permite comprender el proceso subyacente de la escritura, que se presenta como una necesidad. La implicación personal del autor lo obliga a regresar sobre acontecimientos cuya responsabilidad le es imputada; la narración post res perditas no puede, por tanto, limitarse a una descripción en bruto de los hechos ni a un simple comentario: para "disculpar" a su autor, éste debe restaurar una especie de "verdad" que sólo puede ser alcanzada pasando por una reconstrucción minuciosa de los antecedentes, fundada en el cruce de fuentes confiables. ${ }^{77}$ Las Orationes de 1527 participan del mismo esfuerzo de racionalización de la experiencia personal del florentino, al igual que la Historia de Italia, que abre con la elección reivindicada por el autor/narrador de relatar las transformaciones que sacudieron la península itálica a partir de 1494: "lo ho deliberato di scrivere le cose accadute alla memoria nostra in Italia...". ${ }^{78}$

Así, por una especie de paradoja que le encanta a la Historia, mientras que Sanudo -quien ambicionaba convertirse en un profesional de la escritura de la Historia y recopiló para estos fines los materiales más dispares- no vio materializarse su deseo y, por tanto, nunca dio el salto cualitativo que distingue al reportero del historiador, Guicciardini fue obligado por las vueltas del destino a componer - para redimirse- la historia que se convertiría, tal vez en contra de su propia voluntad, ${ }^{79}$ en una de las mayores obras historiográficas de todos los tiempos.

\section{Bibliografía}

Albertini, Rudolf von. Firenze dalla repubblica al principato. Turín: Einaudi, 1995. Bardini, Marco. Borbone occiso: studi sulla tradizione storiografica del sacco di Roma del 1527. Pisa: Tip. Editrice Pisana, 1991.

\footnotetext{
77 Son precisamente estos dos aspectos del gran fresco histórico de Guicciardini los que harán que Jean Bodin califique al autor florentino de historiae parente, en Methodus ad facilem historiarum cognitionem (París: Martin le Jeune, 1566), 63.

${ }^{78}$ Histoire d'Italie, I, 1, en Guicciardini, Opere, 87. Traduzco: "He decidido, por mi parte, escribir las cosas que ocurrieron en nuestros tiempos en Italia...".

79 Muy al estilo virgiliano, según una carta de Annibale Rucellai a Francesco Vettori, el autor habría pedido en su lecho de muerte que se quemara su obra histórica. Véase Emanuele Cutinelli-Rèndina, Guicciardini (Roma: Salerno, 2009), 73, n. 86.
} 
Berchet, Guglielmo. Prefazione ai Diarii di Marino Sanudo. Venecia: Istituto Veneziano per la Storia Patria, 1902.

Calvi, Emilio. Bibliografia di Roma nel Cinquecento. I. Roma: Loescher, 1910.

Caprio, Vincenzo de. "Nei testi del '27: conoscere attraverso la crisi". Annali di Italianistica 2 (1984): 81-93.

Caprio, Vincenzo de. La tradizione e il trauma, idee del Rinascimento romano. Manziana: Vecchiarelli, 1991.

Chastel, André. Le sac de Rome, 1527. Du premier maniérisme à la contre-réforme. París: Gallimard NRF, 1984.

Cutinelli-Rèndina, Emanuele. Guicciardini. Roma: Salerno, 2009.

Di Pierro, Antonio. Il sacco di Roma: 6 maggio 1527. Milán: Mondadori, 2003.

Dizionario biografico degli italiani. Roma: Treccani, 74 vols. Istituto della Enciclopedia Italiana, 1960-2010. Disponible en http://www.treccani.it/biografie/.

Finlay, Robert. "Politics and History in the Diary of Marino Sanuto". Renaissance Quarterly 33, núm. 4 (1980): 585-598.

Fournel, Jean-Louis. "Du jugement de soi au tribunal de l'Histoire: I'analyse immédiate de la défaite dans les écrits de Francesco Guicciardini après le sac de Rome (1527-1530)". En L'Actualité et sa mise en écriture dans l'Italie des $X V^{e}-X V I I^{e}$ siècles, editado por Danielle Boillet y Corinne Lucas, 85-102. París: CIRRI, 2005.

Frediani, Andrea. Il sacco di Roma. Florencia: Giunti, 1997.

Gouwens, Kenneth. Remembering the Renaissance: Humanist Narratives of the Sack of Rome. Leiden: Brill, 1998.

Gouwens, Kenneth y Sheryl E. Reiss (eds.). The Pontificate of Clement VII. History, Politics, Culture. Aldershot: Ashgate, 2005.

Guicciardini, Francesco. Carteggi, editado por Roberto Palmarocchi y Pier Giorgio Ricci. Roma: Istituto Storico Italiano per l'Età Moderna e Contemporanea, 1938-1972. 17 vols.

Guicciardini, Francesco. Opere, editado por Emanuella Lugnani Scarano. Turín: UTET, 1970. 3 vols.

Guicciardini, Francesco. Le lettere, editado por Pierre Jodogne. Roma: Istituto Storico Italiano per l'Età Moderna e Contemporanea, 1986-2008. 10 vols.

Guicciardini, Francesco. Histoire d'Italie, traducido por Jean-Louis Fournel y Jean-Claude Zancarini. París: Robert Laffont, 1996. 2 vols.

Guicciardini, Francesco. Écrits politiques. Discours de Logroño. Dialogue sur la façon de régir Florence, traducido por Jean-Louis Fournel y Jean-Claude Zancarini. París: PUF, 1997. 
Guicciardini, Francesco. Consolatoria, Accusatoria et Defensoria, editado por Florence Courriol. París: Classiques Garnier, 2013.

Hook, Judith. The Sack of Rome. Londres: MacMillan, 1972.

Lugnani Scarano, Emanuella. "La crisi del 1527 e la ricerca di una nuova direzione". En Emmanuella Lugnani Scarano. La ragione e le cose: tre studi su Guicciardini, 124-135. Pisa: ETS, 1980.

Marietti, Marina. "L'évocation du sac de Rome par le florentin Francesco Vettori". En Augustin Redondo (ed.). Les discours sur le sac de Rome de 1527, pouvoir et littérature. París: Presses Sorbonne Nouvelle, 1999.

Marietti, Marina. "La 'ruine de I'Italie'. La fin tronquée des Istorie Fiorentine de Machiavel". En Les guerres d'Italie, editado por Danielle Boillet y Marie-France Piéjus, 337-351. París: Presses Sorbonne Nouvelle, 2002.

Miesse, Hélène. Un laboratorio di carte. Il linguaggio della politica nel 'carteggio' di Francesco Guicciardini. Estrasburgo: ELiPhi, 2017.

Miglio, Massimo, Vincenzo de Caprio, Daniel Arasse y Alberto Asor Rosa (eds.). Il Sacco di Roma del 1527 e l'immaginario collettivo. Roma: Istituto Nazionale di Studi Romani, 1986.

Milanesi, Carlo. II Sacco di Roma del MDXXVII. Narrazioni di contemporanei. Florencia: Barbèra, 1867.

Moreno, Paola. "Il carteggio guicciardiniano, fabbrica della Storia d'Italia". En La "Storia d'Italia" di Guicciardini e la sua fortuna, editado por Claudia Berra y Anna Maria Cabrini, 67-87. Milán: Cisalpino, 2012.

Moreno, Paola. "Quando l'autore corregge se stesso. Il caso unico del copialettere di Francesco Guicciardini". En Epistolari dal Due al Seicento. Modelli, questioni ecdotiche, edizioni, cantieri aperti. Atti del XVI Convegno internazionale di letteratura italiana "Gennaro Barbarisi", editado por Claudia Berra. (Gargnano del Garda, 29-30 de septiembre - 1 de octubre de 2014), en prensa.

Piéjus, Marie-France. "La destruction fondatrice: le prologue des Hecatommiti de Giraldi Cinzio (1565)". En Les discours sur le sac de Rome de 1527, pouvoir et littérature, editado por Augustin Redondo, 137-150. París: Presses Sorbonne Nouvelle, 1999, 137-150.

Ponsiglione, Giulia. La "Ruina" di Roma. II Sacco del 1527 e la memoria letteraria. Roma: Carocci, 2010.

Quattrocchi, Samanta. "'La ruina di questa desolatissima città: il sacco di Roma visto da Marin Sanudo". Tesis de laurea trienal, Universidad de Padua, 2015.

Ridolfi, Roberto. Vita di Francesco Guicciardini. Milán: Rusconi, 1982 [1960]. 
Romei, Danilo. Diari del sacco di Roma di Marin Sanudo. [s. I.]: Lulu, 2016. Disponible en http://www.nuovorinascimento.org/n-rinasc/testi/pdf/sacco/sanudo_nr.pdf.

Sanuto, Marino. I Diarii (MCCCCXCVI-MDXXXIII), editado por Rinaldo Fulin, Federico Stefani, Niccolò Barozzi, Gugliemo Berchet y Marco Allegri. Venecia: Fratelli Visentini, 1879-1902. 58 vols.

Simonetta, Marcello. "La Storia d'Italia del pennaruolo. Accuse autobiografiche contro Guicciardini". En Encyclopaedia mundi. Studi di letteratura italiana in onore di Giuseppe Mazzotta, editado por Stefano U. Baldassarri y Alessandro Polcri, 113-147. Florencia: Le Lettere, 2013.

Solari, Giovanna. Il sacco di Roma. Milán: Mondadori, 1981.

Viallon-Schoneveld, Marie-Françoise. "Infortune e fortune d'un historiographe vénitien: Marin Sanudo". En L'Histoire et les historiens au XVle siècle. Actes du VIII Colloque du Puy-en-Velay, editado por Marie-Françoise Viallon-Schoneveld, 27-42. Saint-Étienne: Publications de l'Université de Saint-Étienne, 2001. Consultado el 29 de junio de 2009. http://hal.archives-ouvertes.fr/ docs/00/15/88/62/PDF/Marino_Sanudo.pdf.

Vivo, Filippo de. Information and Communication in Venice. Rethinking Early Modern Politics. Oxford: Oxford University Press, 2007.

Vivo, Filippo de. Patrizi, informatori, Barbieri, política e comunicazione a Venezia nella prima età moderna. Milán: Feltrinelli, 2012.

Zancarini, Jean-Claude. "'Questa miseranda tragedia'. Le sac de Rome, la providence, la politique". Cahiers d'Études Italiennes 19 (2014): 111-125. Consultado el 4 de septiembre de 2017. http://cei.revues.org/2142. 